\title{
EFEITOS DO SULFATO DE BÁRIO NA CAVIDADE PLEURAL DE RATOS
}

\section{EFFECTS OF BARIUM SULPHATE IN RATS PLEURAL CAVITY}

\author{
Giovanni Antonio Marsico, TCBC-RJ ${ }^{1}$ \\ Rui Haddad, TCBC-RJ ${ }^{2}$ \\ Carlos Eduardo de Souza Carvalho ${ }^{3}$ \\ Patrícia Gioia de $\mathrm{Assis}^{4}$ \\ Ivam Martinelli Júnior ${ }^{5}$ \\ Maria Das Graças Martins ${ }^{6}$
}

\begin{abstract}
RESUMO: Objetivo: Avaliar os efeitos do sulfato de bário na cavidade pleural de ratos. Método: Foram avaliados, experimentalmente, os efeitos do sulfato de bário a $100 \%$ na cavidade pleural de 43 ratos. Sob anestesia inalatória com éter, foi realizada injeção de contraste radiológico $(1 \mathrm{ml})$ na cavidade pleural direita após punção com agulha romba pela via subxifóide. Os ratos, divididos em três grupos, foram mortos em câmara fechada com éter, após $24 \mathrm{~h}$ (13 ratos), 48h (16 ratos) e 21 dias (14 ratos), respectivamente. Através de esternotomia longitudinal e laparotomia alta, foram retiradas a pleura parietal e visceral, juntas com o gradil costal e o pulmão direito. No grupo-controle, de 22 ratos, foi injetado $1 \mathrm{ml}$ de soro fisiológico a $0,9 \%$ na cavidade pleural direita. Resultados: Não houve mortes entre os 43 ratos em que foi injetado sulfato de bário e no grupo-controle. As alterações encontradas na cavidade pleural dos grupos injetados com sulfato de bário e mortos com $24 \mathrm{~h}$ e $48 \mathrm{~h}$ foram semelhantes: leve e difusa hiperemia na pleura parietal, sulfato de bário livre, derrame pleural inflamatório com predomínio de polimorfonucleares; macrófagos na pleura fagocitando sulfato de bário e pleura com infiltrado predominantemente polimorfonuclear. Com 21 dias, o sulfato de bário estava localizado e bloqueado na região retroesternal e havia formação de sínfises pleurais intensas. No exame histopatológico das pleuras havia grande quantidade de macrófagos repletos de sulfato de bário, raros pigmentos de sulfato de bário no meio extracelular, importante proliferação fibroblástica em 13/14 (92\%) casos e não ocorreu formação de granulomas. No grupo-controle (22 ratos), o exame histopatológico foi normal em todas as fases do experimento. Conclusões: a) o sulfato de bário causou derrame pleural inflamatório em todos os casos; b) com 21 dias ocorreu formação de sínfises pleurais em $100 \%$ dos casos; c) não houve formação de granuloma; d) em todas as fases do experimento não ocorreram óbitos.
\end{abstract}

Descritores: Pleura; Sulfato de bário; Pleurodese.

\section{INTRODUÇÃO}

Nas lesões do esôfago a morte ocorre em $20 \%$ a $50 \%$ dos casos quando o diagnóstico e o tratamento não são estabeleci- dos de imediato. Os contrastes radiológicos desempenham papel fundamental na identificação precoce da lesão. Entretanto, alguns questionamentos relacionados especificamente com o estudo das perfurações do esôfago são levantados ${ }^{1-6}$ :

1. Cirurgião de Tórax do Instituto de Doenças do Tórax-UFRJ. Cirurgião de Tórax do Hospital Geral do Andaraí-RJ. Doutor em Cirurgia Setor Tórax - UFRJ

2. Professor Adjunto do Departamento de Cirurgia da Faculdade de Medicina da UFRJ e Chefe do Serviço de Cirurgia de Tórax do Hospital Universitário Clementino Fraga Filho - UFRJ. Doutor em Cirurgia Setor Tórax - UFRJ

3. Chefe do Serviço de Patologia do Instituto de Doenças do Tórax-UFRJ

4. Patologista do Instituto de Doenças do Tórax-UFRJ

5. Chefe do Serviço de Cirurgia de Tórax do Hospital Naval Marcílio Dias-RJ

6. Veterinária do Instituto de Pesquisas Biomédicas do Hospital Naval Marcílio Dias-RJ

Recebido em 16/08/2000

Aceito para publicação em 22/7/2001

Trabalho realizado no Instituto de Pesquisas Biomédicas do Hospital Naval Marcílio Dias, no Serviço de Cirurgia Experimental do Departamento de Cirurgia da Faculdade de Medicina da Universidade Federal do Rio de Janeiro e no Serviço de Patologia do Instituto de Doenças do Tórax da Universidade Federal do Rio de Janeiro. 
a) Quais os efeitos adversos, locais ou sistêmicos, causados pelos contrastes radiológicos usados nos variados tipos de lesão esofágica?

b) Qual seria o contraste mais apropriado para ser administrado nas diversas situações clínicas?

c) Existe contraste radiológico ideal para todas as ocasiões?

A escolha deve ser baseada, em três aspectos: evitar danos locais e sistêmicos ao paciente, alto índice de acurácia diagnóstica, ser de fácil obtenção e baixo custo. $\mathrm{O}$ sulfato de bário é considerado, pela maioria dos autores, o contraste radiológico ideal para detectar perfurações no trato gastrintestinal 1,4,7-11.

A análise do efeito causado pela substância, quando extravasada para a cavidade pleural, é baseada na avaliação e evolução clínicas. Os poucos e relevantes estudos existentes são experimentais e realizados, principalmente, na cavidade abdominal de animais e que foram extrapolados para o tórax ${ }^{1,2,12-14}$.

O presente estudo visa avaliar experimentalmente, em ratos, os efeitos locais, precoces e tardios, causados pela injeção de sulfato de bário na cavidade pleural.

\section{MÉTODO}

Foram usados ratos da raça Long Evans, todos machos, pesando em média 350g (300-400g). A técnica operatória empregada, foi idêntica a utilizada e padronizada previamente por Haddad ${ }^{15}$. Após anestesia inalatória com éter procedeu-se à anti-sepsia com álcool iodado na região subxifóide e infiltração no local de xilocaína a 1\%. Nesta região, foi realizada incisão com cerca de $1 \mathrm{~mm}$ interessando a pele. Isto facilitou a entrada da agulha de peridural (de ponta romba e menos traumática) utilizada na punção. A angulação correta, para introdução da agulha em relação à pele, é de cerca de 25 a 30 graus em direção à clavícula direita do rato. $\mathrm{O}$ diafragma foi perfurado e a cavidade pleural direita era alcançada. A penetração da agulha, pela via subxifóide, não deveria ultrapassar $2 \mathrm{~cm}$ no seu total. O cuidado evitou que se injetasse a substância na parede torácica lateral. Ao término do procedimento os ratos eram colocados em câmara de oxigênio, para recuperação anestésica.

Nos ratos, a pleura mediastinal no seu terço inferior é descontínua, o que permite a livre comunicação entre as cavidades pleurais. Estudos experimentais realizados anteriormente ${ }^{15}$ mostraram que o volume necessário da substância a ser injetada na cavidade pleural direita do rato deve ser o dobro, sendo assim suficiente para difundir-se pela cavidade pleural única. A quantidade de sulfato de bário, introduzida na cavidade pleural foi calculada tomando-se por base a proporção ponderal entre o adulto médio, de $70 \mathrm{~kg}$, e o rato médio, de $350 \mathrm{~g}$.

Para realização de esofagografia, na busca da perfuração do esôfago torácico, normalmente, são utilizados entre $50 \mathrm{ml}$ e $100 \mathrm{ml}$ de sulfato de bário. Tomamos por base o volume máximo de $100 \mathrm{ml}$ e o consideramos totalmente extravasado para o espaço pleural. Dessa forma, calculamos proporcionalmente, o volume a ser injetado na cavida- de pleural do rato através de uma regra de três; $X=(0,350 \mathrm{~kg}$ x $100 \mathrm{ml}): 70 \mathrm{~kg}$. O volume encontrado foi de $0,5 \mathrm{ml}$ x $2=\underline{1 \mathrm{ml}}$. Este foi o volume de sulfato de bário a $100 \%$, com pH de 7 , preparado em condições assépticas e injetado na cavidade pleural direita de 51 ratos.

Três ratos faleceram em decorrência de problemas anestésicos e os 48 recuperados da anestesia geral, sobreviveram ao longo da experiência. Cinco dos 48 ratos foram excluídos da análise. Em três o sulfato de bário foi injetado na cavidade abdominal e, em dois, na parede torácica direita. Nos $43(89,5 \%)$ ratos restantes, a injeção foi realizada na cavidade pleural direita.

Os ratos foram divididos em três grupos e mortos com $24 \mathrm{~h}$ (13 ratos), 48h (16 ratos) e 21 dias (14 ratos) em câmara fechada, com exposição ao éter, até que ocorresse parada respiratória. Em seguida, através de esternotomia longitudinal e laparotomia alta, foi acessada a cavidade pleural direita. Após análise macroscópica das alterações intrapleurais, eram retiradas a pleura parietal e visceral, juntamente com o gradil costal e o pulmão direito. Os materiais eram colocados em formol tamponado a 10\%, para exame histopatológico.

Nos grupos mortos com 24 e 48 horas, os ratos desenvolveram derrame pleural. Os líquidos foram colhidos separadamente para análise citológica e submetidos a centrifugação, no máximo até duas horas após a colheita. Do sedimento foram preparados dois esfregaços, um corado pelo método de Papanicolau e outro pelo método de MayGrünwald-Giemsa. Um terceiro esfregaço foi confeccionado do bloco celular e corado pela hematoxilina-eosina.

No grupo-controle, constituído de 22 ratos, foi injetado intrapleural à direita, $1 \mathrm{ml}$ de soro fisiológico a $0,9 \%$. Os animais foram mortos da mesma forma e no mesmo intervalo de tempo dos outros grupos: $24 \mathrm{~h}$ ( 7 ratos), $48 \mathrm{~h}$ (7 ratos) e 21 dias (8 ratos).

As peças retiradas foram fixadas em solução de formol tamponado a $10 \%$, assim mantidas entre 24 e 72 horas. Para cada caso, foram preparadas quatro lâminas para estudo histopatológico. Diversos fragmentos de pleura parietal e visceral foram retirados aleatoriamente de locais diferentes, inclusos em parafina, cortados e corados pela técnica da hematoxilina-eosina (HE).

\section{RESULTADOS}

Até as datas predeterminadas para a morte, não ocorreram óbitos entre os 43 ratos em que foi introduzido sulfato de bário e no grupo controle de 22 ratos.

As alterações macroscópicas ocorridas na cavidade pleural dos ratos mortos com 24 horas (13 ratos) e 48 horas (16 ratos), foram semelhantes. Todos desenvolveram derrame pleural amarelo-turvo e inodoro, variando o volume de $1,5 \mathrm{ml}$ a $1,9 \mathrm{ml}$. O sulfato de bário encontravase diluído no líquido pleural formado, disperso e livre em toda a superfície pleural e pulmonar, sendo facilmente removido. Os achados correspondiam à hiperemia pleural parietal discreta e difusa, embora mais intensa à direita, onde havia maior quantidade de sulfato de bário disperso neste local. 
Com 21 dias de evolução, não existia derrame pleural. Em todos os 14 ratos mortos, encontramos por toda a cavidade pleural, com exceção da área localizada na pleura mediastinal, sínfises pleurais firmes já plenamente estabelecidas. As aderências pleurais eram mais intensas à direita $\mathrm{e}$ somente podiam ser desfeitas de maneira cruenta. O sulfato de bário havia se transformado em uma substância pastosa e brancacenta, depositada e bloqueada, unicamente no terço inferior da região retroesternal. Entretanto, não comprimia e nem estava aderido às estruturas e órgãos vizinhos. A retirada foi processada sem dificuldade.

Em todas as fases do experimento, o parênquima pulmonar dos ratos não apresentava alterações macroscópicas que pudessem estar relacionadas à presença do sulfato de bário na cavidade pleural.

No grupo controle, não foram notadas alterações macroscópicas na cavidade pleural e a solução fisiológica foi absorvida antes de 24 horas.

As principais alterações histológicas encontradas nas pleuras visceral e parietal, após 24h, em 13 ratos, foram: deposição de sulfato de bário, predomínio de infiltrado polimorfonuclear com inúmeros macrófagos fagocitando sulfato de bário, principalmente, nas superfícies pleurais. As alterações eram caracteristicamente mais intensas na pleura visceral. Somente em um caso $(7,5 \%)$, o exame histopatológico das pleuras foi considerado normal. Neste mesmo grupo de ratos, o estudo citológico do líquido pleural, evidenciou depósito de sulfato de bário livre no fundo, somado a presença de células polimorfonucleares em torno de $90 \%$.

No estudo histopatológico das pleuras realizado com 48h de evolução, em 16 ratos, foi observado intenso predomínio de polimorfonucleares. Porém, maior número de macrófagos fagocitando o sulfato de bário, agora não apenas na superfície das pleuras, mas também agindo na sua intimidade. A citologia do líquido pleural mostrou aproximadamente $70 \%$ de polimorfonucleares e macrófagos fagocitando o sulfato de bário que ainda se mantinha depositado e livre no fundo.

As alterações histológicas pleurais observadas com 21 dias em 14 ratos foram: grande quantidade de macrófagos repletos de sulfato de bário, com aspecto xantomatoso, nos dois folhetos pleurais e raros pigmentos de sulfato de bário no meio extracelular. As pleuras apresentavam-se edemaciadas com discreto infiltrado linfo-histiocitário. Ocorreu importante proliferação fibroblástica em 13/14 (92\%) casos.

O exame histopatológico do grupo-controle - 22 ratos - foi considerado normal em todos os três grupos estudados.

\section{DISCUSSÃO}

Apesar de não existirem estudos experimentais sobre os efeitos provocados pelo sulfato de bário na cavidade pleural, freqüentemente, nos deparamos na literatura com conclusões baseadas somente em observação clínica eventual ou então com dados extrapolados de estudos realizados na cavidade peritoneal ${ }^{1,2,9,10,16}$.
Os principais óbices ao uso do sulfato de bário dizem respeito à demora na sua absorção, e à possibilidade de formação de granuloma na cavidade pleural e no mediastino. Contudo, constatada a perfuração do esôfago, geralmente há necessidade de correção cirúrgica imediata, com a consequiente retirada do sulfato de bário. Na fase tardia do diagnóstico, freqüentemente a drenagem é o tratamento de escolha, o que permite a saída da maior parte do sulfato de bário retido ${ }^{9,17}$.

Em decorrência de doenças pleurais, pulmonares e pleuropulmonares a pleura exerce participação ativa na resposta inflamatória. As alterações geram situações em que o líquido pode aumentar e modificar a fisiologia local. A mais simples irritação ou lesão pleural é capaz de originar resposta sob a forma de espessamento pleural, hipervascularização e inflamação, inclusive com dilatação dos canais linfáticos e proliferação dos tecidos elásticos. A pleura costuma reagir à agressão de forma pouco variada e algumas das alterações observadas em biópsias de pleura são totalmente inespecíficas ${ }^{18}$.

Nos 29 ratos estudados com $24 \mathrm{~h}$ e $48 \mathrm{~h}$ de evolução, o sulfato de bário no espaço pleural causou derrame pleural amarelo turvo. Após 24h, observamos predomínio de células polimorfonucleares na proporção de $90 \%$. Com $48 \mathrm{~h}$, houve redução na taxa de polimorfonucleares para $70 \%$. Nos dois períodos, o sulfato de bário manteve-se livre na cavidade pleural, porém, com 48 horas, percebia-se a presença de macrófagos fagocitando o sulfato de bário. As alterações e a evolução descritas, normalmente irrompem na reação inflamatória inespecífica do espaço pleural.

Os macrófagos surgem nas efusões pleurais, isolados ou em grupamentos principalmente, como consequiência aos processos inflamatórios. $\mathrm{O}$ achado de leucócitos polimorfonucleares neutrófilos, no líquido pleural, indica sem dúvida, processo inflamatório agudo ${ }^{18,19}$.

A cavidade peritoneal, costuma reagir à presença do sulfato de bário da mesma forma como a de qualquer corpo estranho inerte. A permanência do contraste radiológico, mesmo por curto período, causa irritação, reação tecidual, ascite e adenopatias. $\mathrm{O}$ resultado final é a formação de aderências, granulomas e massas de sulfato de bário. Com a evolução, ocorrem principalmente na serosa intestinal, formação de placas firmes e densas de granulomas e tecido fibroso. Os planos de clivagem são obliterados por aderências fibrosas, dificultando e impedindo a dissecção. As estruturas vitais podem sofrer compressão pela formação de granulomas e evoluir com encarceramento. A retirada do sulfato de bário, da cavidade peritoneal, deve ser realizada, imediatamente, através de lavagens sucessivas com soro fisiológico ${ }^{13,20,21}$.

As principais alterações histológicas encontradas na cavidade abdominal, causadas pelo sulfato de bário, geralmente são caracterizadas por: infiltração histiocitária, células gigantes, granulomas, leucócitos fagocitando sulfato de bário, presença de neutrófilos e de linfócitos e reação fibroblástica. Em alguns casos, foram encontrados numerosos linfonodos regionais e da cadeia torácica, contendo sulfato de bário. Em várias ocasiões, o sulfato de bário e o iopidol, após serem injetados na cavidade abdominal de 
animais, foram detectados acima do diafragma, presentes nos linfonodos diafragmáticos e retroesternais ${ }^{13,20-23}$.

Em nosso estudo não foram observados linfonodos hilares e mediastinais aumentados ou que estivessem macroscopicamente comprometidos, em virtude da presença do sulfato de bário no espaço pleural.

O sulfato de bário quando introduzido na cavidade peritoneal, após algumas horas adere firmemente às alças intestinais, mesentério, peritônio parietal e ao omento, dificultando muito a sua remoção ${ }^{14}$.

Em nosso experimento, até com 48 horas de evolução, a retirada do sulfato de bário da superfície pleural e pulmonar dos ratos foi relativamente fácil. Acreditamos que um dos fatores que tenham contribuído foi a diluição do contraste no derrame pleural reacional formado. A maior parte do sulfato de bário não aderia aos órgãos e às estruturas vizinhas, encontrava-se livre no espaço pleural e o restante depositado sobre as superfícies pleurais. Os órgãos e as estruturas contidas na cavidade pleural são diferentes dos encontrados na cavidade abdominal e mediastinal, o que provavelmente, determina comportamentos diferentes.

Ginai et al. $^{23}$, estudaram a reação causada a introdução de vários meios de contrastes radiológicos no mediastino de ratos. Inicialmente, o sulfato de bário puro localizou-se no espaço extracelular, provocando reação histiocitária. A partir do quarto dia e até o quadragésimo segundo, foi aumentando gradativamente a quantidade de sulfato de bário intracelular e, do oitavo dia em diante, ocorreu formação de granulomas com histiócitos gigantes. Ao término de 42 dias, o sulfato de bário ainda mantinhase visível histológica e radiologicamente, porém, circunscrito ao redor ou atrás da traquéia e(ou) do esôfago. O iopidol, no início, provocou acúmulo de polimorfonucleares entremeados no contraste sob a forma de pó. No segundo dia foi encontrada reação exsudativa fibrinosa ao redor do contraste depositado e entre o quarto e oitavo dia, ocorreu proliferação de fibroblastos e vasos. Ao término de 42 dias percebia-se claramente, granulomas já formados e histiócitos repletos com o meio de contraste, além do surgimento de células gigantes. O iopidol também se mantinha radiológico e histologicamente visível com 42 dias, embora com diminuição da sua densidade. Os contrastes hidrosolúveis: metrizamide, meglumine e diatrozoato, produziram reação tecidual insignificante no mediastino dos ratos. Foram rapidamente absorvidos, não sendo vistos nas radiografias realizadas após 24 horas. Nos grupos estudados, não ocorreram óbitos que pudessem ser atribuídos à presença do sulfato de bário e dos demais contrastes radiológicos no mediastino.

O granuloma expressa o acúmulo focal de monócitos, neutrófilos, linfócitos, plasmócitos e células gigantes epitelióides que se originam, provavelmente, de células coalescentes da série macrófago-monocítica. Considera-se o granuloma como o resultado final da imunidade mediada por células, no qual um antígeno manteve-se no local em virtude da sua baixa solubilidade e difícil degradação, causando, dessa maneira, estimulação antigênica contínua local. Os granulomas ocorrem na imunidade mediada celu- lar a partir de infecções, na hipersensibilidade do tipo tardio a metais e partículas orgânicas e na sarcoidose, onde o antígeno é desconhecido. Os macrófagos que se acumulam em local de inflamação crônica, frequientemente, se diferenciam ainda mais indo formar células epitelióides, ou podem fundir-se para formar células gigantes multinucleadas ${ }^{15,19,24,25}$.

Na cavidade pleural dos ratos, A ação dos macrófagos foi progressiva. Com 24 horas de evolução, percebiase na camada pleural grande número de macrófagos fagocitando o sulfato de bário. Embora, a sua ação estivesse praticamente limitada à superfície das pleuras, ela foi mais importante na pleura visceral. Com 48 horas, houve aumento no número de macrófagos, agora agindo mais profundamente nas pleuras. Ainda nesta fase, no derrame pleural formado foram identificados alguns macrófagos fagocitando o sulfato de bário. Nos ratos mortos com 21 dias, tempo considerado suficiente para a formação de granulomas, as alterações teciduais mais significativas na pleura foram: grande quantidade de macrófagos repletos de sulfato de bário, localizados em ambas as pleuras; raros pigmentos de sulfato de bário no meio extracelular; discreto infiltrado linfo-histiocitário e grande proliferação fibroblástica em 13/14 (92\%) ratos. As alterações histológicas estavam limitadas à camada pleural, respeitando o pulmão. De modo diverso ao que ocorre na cavidade peritoneal e no mediastino, onde a presença do sulfato de bário induziu a formação de granulomas, na cavidade pleural dos ratos isto não foi observado.

Embora não tenhamos realizado controle radiológico, provavelmente, o sulfato de bário ainda seria identificado nas radiografias realizadas com 21 dias. Era evidente a sua presença macroscópica, localizado unicamente na região retroesternal dos ratos. Possuía aspecto brancacento, consistência pastosa e encontrava-se dessecado.

Aparentemente, o sulfato de bário extraperitoneal, representa menor morbidade em relação a sua presença na cavidade abdominal. Contudo, encontramos relatos de formação de granulomas envolvendo e comprimindo o ureter, a parede retal e os tecidos perirretais, com formação de massa dolorosa e estenose retal. A retenção do sulfato de bário na submucosa da parede intestinal, é capaz de causar formação de lesão granulomatosa que pode ulcerar e sangrar ${ }^{1,13}$.

Com 21 dias do nosso experimento não foram observados efeitos compressivos pela presença do sulfato de bário sobre os órgãos ou estruturas contidas na cavidade pleural e mediastino. O sulfato de bário estava limitado e bloqueado à região retroesternal dos ratos.

Alguns estudos mostraram que o sulfato de bário intraperitoneal, mesmo sem a presença de germes patogênicos, foi fatal ${ }^{22,14}$. Almond et al. ${ }^{22}$, introduziram na cavidade peritoneal de 10 cães, $30 \mathrm{ml}$ de sulfato de bário a $30 \%$ em suspensão não esterilizada. Todos evoluíram mal em poucas horas e sete morreram dentro de duas semanas com peritonite generalizada. As mortes foram atribuídas a complicações induzidas pelo sulfato de bário. Porém, ao repetirem o procedimento em cinco animais, agora com $30 \mathrm{ml}$ de sulfato de bário em suspensão aquosa e esterilizada, todos sobreviveram. 
Nahrwold et al..$^{14}$, usaram em 11 cães, $200 \mathrm{ml}$ de sulfato de bário esterilizado em suspensão de $15 \%$. Não retiraram o sulfato de bário intraperitoneal e nem forneceram suporte hidroeletrolítico aos animais. Todos morreram. No grupo ao qual adicionaram líquidos venosos, a mortalidade diminuiu para $20 \%$. Em outro grupo, quando o sulfato de bário foi retirado e foram fornecidos líquidos, a mortalidade foi de $9 \%$. Nestes dois últimos grupos, a diferença na mortalidade não foi considerada significativa. As mortes, foram atribuídas a grande quantidade de sulfato de bário empregado, o que causou ascite volumosa e resultou em grave distúrbio hidroeletrolítico.

Ginai ${ }^{12}$, estudou os efeitos causados por sete tipos diferentes de contrastes radiológicos introduzidos na cavidade peritoneal de ratos. Verificou que o iopidol na dose de $1,5 \mathrm{ml}$ foi altamente letal, causando a morte de todos os ratos em dois dias. As autópsias, evidenciaram o iopidol sob a forma de grumos esbranquiçados, depositados principalmente sobre o grande omento, fígado e mesentério do intestino delgado, além de ascite com líquido acastanhado. A causa exata das mortes, não foi esclarecida.

Em nosso estudo, o sulfato de bário intrapleural não foi letal. No grupo de 43 ratos, não ocorreram mortes até as etapas estabelecidas.

Zheutlin et al. ${ }^{21}$, em decorrência de complicações na realização de enema baritado, encontraram $51 \%$ de mortalidade, causada pela presença de fezes e de sulfato de bário intraperitoneal. A associação sulfato de bário e fezes mostrou-se altamente deletéria quando comparada aos dois agentes isolados. A mortalidade e a morbidade, estão diretamente relacionadas ao volume de bário que entra na cavidade peritoneal associado a outros materiais ${ }^{21,22,26,27}$.

Foram uniformes os resultados encontrados na literatura, quanto aos contrastes radiológicos hidrossolúveis: diatrozoato de sódio, metrizamide e meglumine. A avaliação mostrou que são inócuos na cavidade abdominal e mediastino, não causando qualquer tipo de reação tecidual nessas regiões, sendo rapidamente absorvidos ${ }^{12,17,20,23}$.

James et al. ${ }^{17}$, em 1975, publicaram estudo comparativo realizado entre o sulfato de bário e o contraste iodado (diatrozoato de sódio). Ambos foram introduzidos separados no mediastino de gatos, associados ou não a bactérias da orofaringe. Os animais foram acompanhados clinicamente e por radiografias seriadas, sendo todos mortos ao término de três meses. Naqueles em que o sulfato de bário foi injetado, os achados histopatológicos corresponderam a uma reação inflamatória tipo corpo estranho. Constataram que a formação de granuloma no mediastino foi um fenômeno localizado, que pode ser evitado com a remoção precoce do bário. $\mathrm{O}$ controle radiológico tardio, mostrou o bário retido e bloqueado no mediastino. Após duas semanas constataram a presença de adesões pleurais e com três meses extensas áreas de adesão fibrosa entre a pleura visceral e parietal. Mas, aparentemente, os animais, toleraram bem a mediastinite induzida pelo sulfato de bário. Com o contraste hidrossolúvel não foram encontradas, nos tecidos do mediastino, alterações histológicas imediatas ou tardias. A presença da flora bacteriana oral, junto com o sulfato de bário, não determinou aumento da resposta in- flamatória, quando esta foi comparada com aquela causada pelo sulfato de bário isolado. Entretanto, a crítica a ser feita é o não estabelecimento de critérios relacionando a doseresposta, entre a flora bacteriana e o sulfato de bário. No mediastino dos gatos, foram encontrados grânulos de sulfato de bário e grandes agregados no interior dos macrófagos e nos linfonodos regionais. Os autores, de acordo com os resultados obtidos, concluíram que o sulfato de bário, somado à infecção bacteriana, não aumenta significativamente a resposta inflamatória no mediastino.

Os mesmos autores ${ }^{27}$, publicaram ainda em 1975, a experiência realizada no mediastino de 30 gatos, nos quais foram injetados: sulfato de bário; sulfato de bário + flora normal da boca humana; contraste iodado; contraste iodado + flora normal da boca humana. A inoculação da flora bacteriana no mediastino, foi realizada em diversas concentrações. Os animais foram mortos a intervalos seriados, de acordo com a introdução das substâncias. Com base nos achados, concluíram que, no mediastino: a) o contraste hidrossolúvel não causa reação histológica importante; b) o sulfato de bário causa formação de granuloma, contudo não adiciona efeitos deletérios quando misturado à flora bacteriana com diferentes concentrações.

Foley et al. ${ }^{9}$, avaliaram inicialmente, com contraste radiológico hidrossolúvel, seis pacientes com suspeita de perfuração do trato gastrintestinal. Em todos os casos houve falha no diagnóstico. As perfurações somente foram identificadas quando foi utilizado o sulfato de bário. Quatro perfurações estavam localizadas na cavidade abdominal e duas no mediastino. Nestas, a conduta foi conservadora e o sulfato de bário permaneceu no local. O acompanhamento durante três anos transcorreu sem anormalidades. A abordagem cirúrgica das perfurações localizadas no abdômen foi precoce e o sulfato de bário foi retirado com facilidade.

Nos 14 ratos da nossa experiência em que o sulfato de bário foi mantido durante 21 dias no espaço pleural, em todos os casos ocorreu formação de sínfises pleurais intensas (pleurodese) por toda a cavidade pleural, com exceção da área ocupada pela pleura mediastinal. A separação das pleuras somente foi possível por métodos cruentos. Nesta fase não existia líquido no espaço pleural. Chegou-se, assim, às seguintes conclusões:

1. O sulfato de bário injetado no espaço pleural de ratos, com 24 horas e 48 horas causou derrame pleural inflamatório inespecífico (alterações precoces) em 100\% dos casos.

2. O sulfato de bário intrapleural, com 24 e 48 horas de evolução, causou ainda, hiperemia discreta e difusa na pleura parietal dos ratos.

3. O sulfato de bário mantido na cavidade pleural de ratos, por período mais longo (21 dias), causou proliferação fibroblástica em 13/14 (92\%) ratos e a formação de sínfises pleurais (pleurodese), em 100\% dos ratos.

4. A permanência do sulfato de bário, durante 21 dias, na cavidade pleural de ratos, não induziu a formação de granulomas.

5. Não ocorreram mortes nos ratos submetidos a injeção intrapleural de sulfato de bário. 


\begin{abstract}
Background: Evaluate the effects of barium sulphate in rats pleural cavity. Method: The effects due to the presence of $100 \%$ barium sulphate in the pleural cavity of 43 rats were experimentally assessed. After inhaled ether anesthesia, $1 \mathrm{ml}$ of radiological contrast was injected via subxiphoid through a blunt needle into the right pleural cavity. The animals were divided into 3 groups and were killed with in a closed chamber with ether after $24 \mathrm{hs}$ (13 rats), $48 \mathrm{hs}$ (16 rats) and 21 days (14 rats), respectively. Through a longitudinal sternotomy and laparatomy, both parietal and visceral pleura were extracted along with the rib cage and right lung. Control group was composed of 22 rats which underwent an injection of $1 \mathrm{ml}$ saline $0,9 \%$ into the right pleural cavity. Results: No death occurred in 43 rats injected with barium sulphate nor in the control group. There were similar findings in the pleural cavity of animals (barium sulphate) killed at $24 \mathrm{~h}$ and $48 \mathrm{~h}$ such as diffuse mild hyperemia in right pleura, free barium sulphate, inflammatory pleural effusion with polymorphonuclears predominating, macrophages phagocyting barium sulphate in the pleura, which presented a polymorphonuclear predominant infiltrate. At 21 days, barium sulphate was found localized and blocked in the retrosternal region with, intense formation of pleural symphises. Pleural histopathology revealed large numbers of barium sulphate filled macrophages, scant extra-cellular barium sulphate pigments, important fibroelastic proliferation in 13/14(92\%) cases, without granuloma formation. Histopathology of 22 rats of the control group was considered normal throughout the experiment. Conclusions: Barium sulphate caused inflammatory pleural effusion in all cases; with no granuloma formation; and no deaths troughout the experiment.
\end{abstract}

Key Words: Pleural; Barium sulphate; Pleural symphises.

\section{REFERÊNCIAS}

1. Dodds WJ, Stewart ET, Vlymen WJ - Appropriate Contrast Media for Evaluation of Esophageal Disruption. Radiology, 1982; 144:439-441.

2. Marsico GA. Efeitos do sulfato de bário na cavidade pleural de ratos. Tese UFRJ, Faculdade de Medicina, 1998.

3. Marsico GA, Azevedo DE, Guimarães CA, et al. - Ferimentos e Lesões do Esôfago. JBM 1998; 74:19-36.

4. Marsico GA, Montessi J, Capone D - Lesões do Esôfago. JBM, 1996; 71:83-90.

5. Triggiani E, Belsey R - Oesophageal trauma: incidence, diagnosis and management. Thorax, 1977; 32:241-249.

6. Whyte RI, Iannettoni MD, Orringer MB - Intrathoracic Esophageal Perforation. J Thorac Cardiovasc Surg, 1995; 109:140-146.

7. Bell KE, McKinstry S, Mills OM - Iopamidol in the Diagnosis of Suspected Upper Gastro-intestinal Perforation. Clinical Radiology, 1987; 38:165-168.

8. Feliciano DV, Bitondo CG, Mattox KL et al. - Combined Tracheoesophageal Injuries. Am J Surg, 1985; 150:710-715.

9. Foley MJ, Ghahremani GG, Rogers LF - Reapraisal of Contrast Media Used To Defect Upper Gastrointestinal Perforations. Radiology, 1982; 144:231-237.

10. Phillips LG, Cunningham J - Esophageal Perforation. Radiologic Clinics of North America, 1984; 22:607-613.

11. Popovsky J, Lee YC, Berk JL - Gunshot wounds of the esophagus. J Thorac Cardiovasc Surg, 1976; 72:609-612.

12. Ginai AZ - Experimental evaluation of various available contrast agents for use in the gastrointestinal tract in case of suspected leakage: Effects on peritoneum. British Journal of Radiology, 1985; 58:969-978.

13. Herrington JL- Barium Granuloma Within the Peritoneal Cavity: Ureteral Obstruction 7 Years after Barium Enema and Colonic Perforation. Ann Surg, 1966; 164:162-166.

14. Nahrwold DL, Isch JH, Benner DA, et al. - Effect of fluid administration and operation on the mortality rate in barium peritonitis. Surg, 1971; 70:778-782.

15. Haddad R. Alterações histopatológicas pulmonares na pleurodese química. Estudo experimental em ratos. Rio de Janeiro, Tese UFRJ, Faculdade de Medicina, 1995.

16. Silva HFA, Lima RD, Martinho JM, et al. - Diagnóstico radiológico das perfurações esofagianas. Arq Bras Med, $1988 ; 62: 349-351$.
17. James Jr. AE, Montali RJ, Chaffee V, et al. - Barium or Gastrografin: Wich Contrast Media For Diagnosis Of Esophageal Tears? Gastroenterology, 1975; 68:1103-1113.

18. Rodriguez-Panadero F, Antony VB - Pleurodesis: state of the art. Eur Respir J, 1997; 10:1648-1654.

19. Miserocchi G. Physiology and pathophysiology of pleural fluid turnover. Eur Resp J, 1997; 10:219-225.

20. Ferrante LS, Schreiman JS, Rouse JW, et al. - Iopamidol as a Gastrointestinal Contrast Agent. Investigative Radiology 1990; 25:141-145.

21. Zheutlin N, Lasser EC, Rigler LG - Clinical Studies on Effect Of Barium In The Peritoneal Cavity Following Rupture Of The Colon. Surg, 1952; 32:967-979.

22. Almond CH, Cochran DQ, Shucart WA - Comparative Study of the Effects of Various Radiographic Contrast Media on the Peritoneal Cavity. Ann Surg, 1961; 154:219-224.

23. Ginai AZ, Kate FJW, Hoornstra K - Experimental evaluation of various available contrast agents for use in the upper gastrointestinal tract in case of suspected leakage: effects on mediastinum. British Journal of Radiology, 1984; 58:585-592.

24. Baumann MH, Heinrich K, Sahn SA, et al. - Pleural macrophages differentially after mesothelial growth and collagen production. Inflamation, 1993; 17:1-12.

25. Wang NS - The Preformed Stomas Connecting the Pleural Cavity and the Lymphatics in the Parietal Pleura. Am Rev Resp Dis, 1975; 111:12-19.

26. Gardiner H, Miller RE - Barium Peritonitis. Am J Surg, 1973; 125:350-352.

27. Vessal K, Montali RJ, Larson SM, et al. - Evaluation Of Barium And Gastrografin As Contrast Media For The Diagnosis Of Esofageal Ruptures or Perforations. American Journal of Rontgenology, 1975; 123:307-308.

Endereço para correspondência:

Giovanni Antonio Marsico

Hospital Universitário Clementino Fraga Filho-UFRJ s/n Ilha do Fundão

Serviço de Cirurgia de Tórax sala 10E/22 - 10 andar CEP 21940-590

E-mail: marsicog@gbl.com.br 